\title{
SF3A1 and pancreatic cancer: new evidence for the association of the spliceosome and cancer
}

\author{
Jing Tian ${ }^{1, *}$, Yaping Liu ${ }^{1, *}$, Beibei Zhu², Yao Tian ${ }^{1}$, Rong Zhong $^{2}$, Wei Chen², Xinghua \\ $\mathrm{Lu}^{3}$, Li Zou ${ }^{2}$, Na Shen ${ }^{2}$, Jiaming Qian ${ }^{3}$, Hui Li ${ }^{1}$, Xiaoping Miao ${ }^{2}$, Li Wang ${ }^{1}$ \\ ${ }^{1}$ Department of Epidemiology and Biostatistics, Institute of Basic Medical Sciences Chinese Academy of Medical Sciences, \\ School of Basic Medicine Peking Union Medical College, Beijing, China \\ ${ }^{2}$ State Key Laboratory of Environment Health (Incubation), MOE (Ministry of Education) Key Laboratory of Environment \& Health, \\ Ministry of Environmental Protection Key Laboratory of Environment and Health (Wuhan), and Department of Epidemiology and \\ Biostatistics, School of Public Health, Tongji Medical College, Huazhong University of Science and Technology, Wuhan, China \\ ${ }^{3}$ Division of Gastroenterology, Peking Union Medical College Hospital, Chinese Academy of Medical Sciences, Peking Union \\ Medical College, Beijing, China \\ *These authors have contributed equally to this work
}

Correspondence to:

Li Wang, e-mail: liwang@ibms.pumc.edu.cn

Xiaoping Miao, e-mail: miaoxp@mail. hust.edu.cn

Keywords: pancreatic cancer, RNA splicing, genetic variants, smoking, drinking

Received: June 22, 2015

Accepted: October 05, 2015

Published: October 15, 2015

\section{ABSTRACT}

\begin{abstract}
A two-stage case-control study was conducted to examine the association between six candidate U2-depedent spliceosome genes (SRSF1, SRSF2, SF3A1, SF3B1, SF1 and PRPF40B) and pancreatic cancer (PC). Subjects with one or two T alleles at rs2074733 in SF3A1 had a lower risk of PC compared to those with two C alleles in combined two populations (OR: $0.59,95 \%$ confidence interval: $0.48-0.73$, False discovery rate $(F D R)-P=1.5 E-05)$. Moreover, the presence of the higher-risk genotype at rs2074733 plus smoking or drinking had synergic effects on PC risk. These findings illustrate that RNA splicing-related genes appear to be associated with the occurrence of PC, and show synergic interactions with smoking and drinking in the additive model. In the future, our novel findings should be further confirmed by functional studies and independent large-scale population studies.
\end{abstract}

\section{INTRODUCTION}

Pancreatic cancer (PC), which is a highly malignant tumor associated with poor prognosis [1], is the fourth leading cause of cancer death in the United States, with an estimated 38,460 deaths in 2013 [2]. Also, the mortality rate in China have been risen gradually since 1991 [3]. PC is caused by the interaction of environmental and genetic factors. Although many environmental factors (e.g., cigarette smoking, alcohol drinking and dietary factors) have been associated with the development of PC, smoking is the only confirmed factor $[1,4]$. With respect to the germline variation of $\mathrm{PC}$, multiple genes including BRCA2, PALB2, ATM, the ABO loci, NR5A2, CLPTM1L-TERT, BACH1, DAB2, and FAM19A5, have been shown to be associated with the progression of PC [1,5-9]. However, although many genetic factors have been identified, their PC-related interactions with environmental factors have not yet been fully elucidated.

As the field of cancer genomics continues to expand, scores of new cancer genes have been revealed, including genes involved in RNA splicing [10]. RNA splicing is an essential function in almost all eukaryotic organisms. During this process, introns are removed from pre-messenger RNAs; splicing factors recognize specific-sequences in the pre-RNA; and the spliceosome connects the exons. There are two types of spliceosomes, the major U2-dependent spliceosomes and the minor U12-dependent spliceosomes, which recognize the major U2- and minor U12-dependent intron groups, respectively [11]. During U2-dependent intron recognition, a number of factors play prominent roles, including: the U1 small nuclear ribonucleoproteins (U1 snRNPs) responsible for recognizing 5'-splice site 
(5'SS); splicing factor1 (SF1), which binds the branchsite A residue; the $\mathrm{U} 2$ small nuclear ribonucleoprotein auxiliary factor 35/65 (U2AF35/65) heterodimer responsible for recognizing the $3^{\prime}$-splice site ( 3 'SS) by binding the $\mathrm{AG}$ dinucleotide and the downstream polypyrimidine tract of the branch site; and the serinearginine (SR) rich family of RNA-binding proteins (e.g., SRSF1 and SRSF2), which can bind to splicing enhancers through the arginine -serine rich domain and recruit the U1 snRNP and U2AF to the $5^{\prime}$ or $3^{\prime} \mathrm{SS}$. SF3B1, splicing factor 3b, subunit 1, which encodes the SF3b1 protein, helps the U2 snRNP bind to the 3'SS with SF3a1 (Supplementary Figure S1).

Recent studies have shown that some spliceosome genes involved in the early steps of U2-dependent splice site recognition are commonly mutated in hematologic malignancies and solid cancers [12-18]. For example, exome-sequencing studies found that SF3B1 was mutated in $10-15 \%$ of patients with chronic lymphocytic leukemia, while other spliceosome genes (e.g. SRSF1, SRSF7 and U2AF65) were mutated at lower (but still detectable) frequencies in chronic lymphocytic leukemia patients $[12,13]$. In myelodysplastic syndrome, spliceosome genes were reported to be mutated in $45-85 \%$ of patients; mutations were commonly found in SF3B1, SRSF2 and $\mathrm{U} 2 \mathrm{AF} 35$, and also found (albeit at lower frequencies) in SF3A1, PRPF40B, U2AF65 and SF1 [14]. Finally, the U2-dependent spliceosome proteins, SF3B1, U2AF35, U2AF65, and PRRF40B, are significantly mutated in solid tumors of lung adenocarcinomas [15], while mutations in SF3B1 have been associated with breast cancer, uveal melanoma, and PC [16-18].

Although genetic variants of the spliceosome complex are generally believed to play a causative role in cancer, relatively few association studies have been performed on solid tumors, especially PC. We have already verified the association between genetic polymorphism of U2AF35/U2AF65 with PC and revealed the interaction of U2AF65 and smoking may increase the risk of PC previously [19]. Subjects with C allele in rs310445 of U2AF65 gene had a 1.31-fold risk to be associated with pancreatic cancer compared to those with TT genotype $(p=0.010)$. A synergic effect of smoking and $\mathrm{C}$ allele of rs310445 was also observed, with synergic index (SI) of 2.08 (95\% confidence interval (CI): 1.37-2.78) [19]. Here, we selected other six U2-dependent spliceosome genes previously shown to have cancer-associated mutations (SRSF1, SRSF2, SF3A1, SF3B1, SF1 and PRPF40B), and screened 17 putative tag single nucleotide polymorphisms (tagSNPs) in these genes. We used a two-stage case-control study, in which two independent Chinese populations were taken as the screening and validation populations, and used to explore the genetic effect of U2-dependent spliceosomes on PC susceptibility. We also examined potential gene-environment interactions between the identified variant, smoking status, drinking status, and $\mathrm{PC}$ risk.

\section{RESULTS}

\section{Subject characteristics}

Five samples ( 2 cases and 3 controls) with call rates less than 95\% were excluded. 298 PC cases and 525 controls were finally included in the screening stage, and 413 PC cases and 557 controls were included in the validation stage. The characteristics of the subjects are summarized in Table 1. There was no significant

Table 1: Characteristics of subjects in this two-stage case-control study

\begin{tabular}{|c|c|c|c|c|c|c|}
\hline & \multicolumn{3}{|c|}{ Screening Stage } & \multicolumn{3}{|c|}{ Validation Stage } \\
\hline & $\begin{array}{l}\text { Controls } \\
(N=525)\end{array}$ & $\begin{array}{c}\text { Cases } \\
(N=298)\end{array}$ & $P$ & $\begin{array}{l}\text { Controls } \\
(N=557)\end{array}$ & $\begin{array}{c}\text { Cases } \\
(N=413)\end{array}$ & $P$ \\
\hline $\begin{array}{l}\text { Age }(\text { mean } \pm \mathrm{SD}) \\
\text { years }\end{array}$ & $58.9 \pm 12.9$ & $60.3 \pm 12.8$ & 0.132 & $59.0 \pm 13.3$ & $58.6 \pm 13.1$ & 0.630 \\
\hline \multicolumn{7}{|l|}{ Gender } \\
\hline Male(\%) & $260(49.5)$ & $164(55.0)$ & 0.129 & $341(61.2)$ & $254(61.5)$ & 0.929 \\
\hline Female $(\%)$ & $265(50.5)$ & $134(45.0)$ & & $216(38.8)$ & $159(38.5)$ & \\
\hline \multicolumn{7}{|l|}{ Smoking status } \\
\hline Never $(\%)$ & $403(76.8)$ & $192(64.4)$ & $<0.001$ & $365(65.5)$ & $241(58.4)$ & 0.023 \\
\hline Ever(\%) & $122(23.2)$ & $106(35.6)$ & & $192(34.5)$ & $172(41.7)$ & \\
\hline \multicolumn{7}{|l|}{ Drinking status } \\
\hline Never(\%) & $412(78.5)$ & $219(73.5)$ & 0.104 & $376(67.5)$ & $275(66.6)$ & 0.763 \\
\hline Ever(\%) & $113(21.5)$ & $79(26.5)$ & & $181(32.5)$ & $138(33.4)$ & \\
\hline
\end{tabular}


difference in the age or gender distribution between PC patients and controls in either population. The proportions of smokers and drinkers among the cases were higher than those among the controls. However, only smoking was significantly associated with the risk of PC in both populations. The odds ratios (ORs) for smoking in PC patients of the screening and validation populations were 1.82 (95\% CI: $1.34-2.49)$ and $1.36(95 \%$ CI: $1.04-1.76)$, respectively.

\section{Genotyping and assessing the associations between SNPs and PC}

In the screening population, we detected the genotyping of 17 tagSNPs in six candidate genes. Three SNPs (rs11231868 in SF1, rs5749066 and rs5749068 in SF3A1) deviated significantly from Hardy-Weinberg Equilibrium (HWE) in the control group [False discovery rate (FDR)-P $<0.05]$, and were thus excluded from the analysis (Supplementary Table S1). Therefore, 14 SNPs were included in our analysis. Among them, six SNPs in three genes showed potential associations with PC: rs4073998 and rs8626 in PRPF40B; rs2074733, rs5994293 and rs9608886 in SF3A1; and rs8819 in SRSF1. These SNPs were significantly different between the patient and control groups after we adjusted for age, gender (Supplementary Table S2). The same trend was still existed after adjusted for age, gender, smoking and drinking. The P values after FDR correction were 0.014, 5.5E-05, 0.014, 0.023, 0.014 and 0.001 , respectively. The ORs and 95\%CIs are summarized in Table 2. Further analysis showed evidence for strong linkage disequilibrium between rs4073998 and rs8626 (D' = $0.964, r^{2}=0.717$ ). Therefore, five SNPs (rs4073998 in PRPF40B; rs2074733, rs5994293 and rs9608886 in SF3A1 and rs8819 in SRSF1) were selected for further validation.

Genotyping of these five SNPs was performed in the larger validation population of $413 \mathrm{PC}$ cases and 557 controls. All of the tested SNPs conformed to HWE in the control group. Interestingly, only rs2074733 was significantly different between PC cases and controls after we adjusted for age, gender, smoking and drinking. Compared with the CC genotype, subjects with the TT or CT genotypes had a lower risk of PC [OR 0.54 (95\%CI: 0.41-0.73); FDR-P = 3.0E-04] (Table 3).

We further analyzed the effect of rs2074733 in the combined populations of the two stages, and the resultant P value for the Breslow-Day homogeneity test was 0.396 . In agreement with the abovementioned results, rs2074733 was significantly associated with PC risk in the combined population. Subjects with one or two T alleles had a lower

Table 2: Effects of 14 tag SNPs from eight RNA splicing-related genes on PC risk in the screening population

\begin{tabular}{|c|c|c|c|c|c|c|c|}
\hline Gene & SNP & Genotypes $^{a}$ & Controls $(N=525)(\%)$ & Cases $(N=298)(\%)$ & OR $(95 \% C I)^{b}$ & $\boldsymbol{P}$ & FDR- $P^{c}$ \\
\hline \multirow[t]{2}{*}{ PRPF $40 B$} & rs4073998 & $(\mathrm{AA}+\mathrm{AG}) / \mathrm{GG}$ & $65(12.4) / 460(87.6)$ & $59(19.8) / 239(80.2)$ & $1.80(1.22-2.67)$ & 0.003 & $0.014 *$ \\
\hline & rs 8626 & $(\mathrm{GG}+\mathrm{AG}) / \mathrm{AA}$ & $71(13.5) / 454(86.5)$ & $78(26.2) / 220(73.8)$ & $2.37(1.64-3.41)$ & $3.9 \mathrm{E}-06$ & $5.5 \mathrm{E}-05^{*}$ \\
\hline$S F 1$ & rs474707 & $(\mathrm{TT}+\mathrm{CT}) / \mathrm{CC}$ & $320(61.0) / 205(39.0)$ & $178(59.7) / 120(40.3)$ & $0.96(0.71-1.28)$ & 0.757 & 0.815 \\
\hline \multirow[t]{7}{*}{$S F 3 A 1$} & rs 12484880 & $(\mathrm{GG}+\mathrm{TG}) / \mathrm{TT}$ & $76(14.5) / 449(85.5)$ & $47(15.8) / 251(84.2)$ & $1.11(0.74-1.66)$ & 0.610 & 0.712 \\
\hline & rs2074733 & $(\mathrm{TT}+\mathrm{CT}) / \mathrm{CC}$ & $366(69.7) / 159(30.3)$ & $179(60.1) / 119(39.9)$ & $0.65(0.48-0.88)$ & 0.005 & $0.014^{*}$ \\
\hline & rs5753081 & $\mathrm{CT} / \mathrm{CC}$ & $29(5.5) / 496(94.5)$ & $15(5.0) / 283(95.0)$ & $0.97(0.51-1.85)$ & 0.928 & 0.928 \\
\hline & rs5994293 & GG/GT/TT & $56(10.7) / 200(38.1) / 269(51.2)$ & $19(6.4) / 102(34.2) / 177(59.4)$ & $0.74(0.59-0.93)$ & 0.01 & $0.023 *$ \\
\hline & rs 7288947 & $(\mathrm{TT}+\mathrm{CT}) / \mathrm{CC}$ & $166(31.6) / 359(68.4)$ & $76(25.5) / 222(74.5)$ & $0.75(0.54-1.03)$ & 0.075 & 0.131 \\
\hline & rs8141656 & $(\mathrm{CC}+\mathrm{CT}) / \mathrm{TT}$ & $261(49.7) / 264(50.3)$ & $164(55.0) / 134(45.0)$ & $1.25(0.94-1.67)$ & 0.130 & 0.202 \\
\hline & rs9608886 & $(\mathrm{GG}+\mathrm{TG}) / \mathrm{TT}$ & $113(21.5) / 412(78.5)$ & $40(13.4) / 258(86.6)$ & $0.55(0.37-0.82)$ & 0.004 & $0.014 *$ \\
\hline$S F 3 B 1$ & rs11683572 & $(\mathrm{GG}+\mathrm{CG}) / \mathrm{CC}$ & $222(42.3) / 303(57.7)$ & $108(36.2) / 190(63.8)$ & $0.74(0.55-1.00)$ & 0.047 & 0.094 \\
\hline \multirow[t]{2}{*}{ SRSF1 } & rs2233911 & $(\mathrm{GG}+\mathrm{AG}) / \mathrm{AA}$ & $170(32.4) / 355(67.6)$ & $114(38.3) / 184(61.7)$ & $1.25(0.92-1.68)$ & 0.151 & 0.211 \\
\hline & rs8819 & $\mathrm{CT} / \mathrm{CC}$ & $21(4.0) / 504(96.0)$ & $32(10.7) / 266(89.3)$ & $3.04(1.69-5.48)$ & $2.1 \mathrm{E}-04$ & $0.001 *$ \\
\hline$S R S F 2$ & rs237059 & $\mathrm{CT} / \mathrm{CC}$ & $6(1.1) / 519(98.9)$ & $1(0.3) / 297(99.7)$ & $0.26(0.03-2.18)$ & 0.212 & 0.270 \\
\hline
\end{tabular}

${ }^{\text {a }}$ The last genotype was used as the reference for OR estimation.

${ }^{\mathrm{b}}$ Adjusted by gender, age, smoking and drinking in the unconditional logistic regression.

${ }^{c}$ Each $P$ value was modified by FDR correction for multiple comparisons (the number of comparisons $=14$ ).

"Significant difference after FDR correction 
Table 3: Effects of five candidate tagSNPs on PC risk in the validation population

\begin{tabular}{|c|c|c|c|c|c|c|c|}
\hline Gene & SNP & Genotypes $^{\mathrm{a}}$ & Controls $(N=557)(\%)$ & Cases $(N=413)(\%)$ & OR $(95 \% C I)^{b}$ & $\boldsymbol{P}$ & FDR- $P^{\mathrm{c}}$ \\
\hline PRPF40B & rs4073998 & $(\mathrm{AA}+\mathrm{AG}) / \mathrm{GG}$ & $67(12.0) / 490(88.0)$ & $54(13.1) / 359(86.9)$ & $1.12(0.76-1.65)$ & 0.563 & 0.669 \\
\hline \multirow[t]{3}{*}{ SF3A1 } & rs2074733 & $(\mathrm{TT}+\mathrm{CT}) / \mathrm{CC}$ & $434(77.9) / 123(22.1)$ & $272(65.9) / 141(34.1)$ & $0.54(0.41-0.73)$ & $3.2 \mathrm{E}-05$ & $3.0 \mathrm{E}-04 *$ \\
\hline & rs5994293 & GG/GT/TT & $37(6.6) / 217(39.0) / 303(54.4)$ & $18(4.4) / 154((37.3) / 241(58.3)$ & $0.85(0.69-1.06)$ & 0.145 & 0.221 \\
\hline & rs9608886 & GT/TT & $18(3.2) / 539(96.8)$ & $21(5.1) / 392(94.9)$ & $1.64(0.86-3.14)$ & 0.132 & 0.221 \\
\hline SRSF1 & rs 8819 & $(\mathrm{CT}+\mathrm{TT}) / \mathrm{CC}$ & $21(3.8) / 536(96.2)$ & $10(2.4) / 403(97.6)$ & $0.62(0.29-1.33)$ & 0.221 & 0.280 \\
\hline
\end{tabular}

The last genotype was used as the reference for OR calculations.

${ }^{\mathrm{b}}$ Adjusted by gender,age,smoking and drinking in the unconditional logistic regression.

${ }^{c}$ Each $P$ value was modified by FDR correction for multiple comparisons (the number of comparisons $=19$ )

*Significant difference after FDR correction.

Table 4: Interactions between smoking, drinking and rs2074733 in the occurrence of $\mathrm{PC}$ in the combined group

\begin{tabular}{|c|c|c|c|c|c|c|c|c|}
\hline & & Controls (\%) & Cases (\%) & OR $(95 \% C I)^{a}$ & $P_{L L R T}$ & SI $(95 \% C I)$ & $\mathrm{AP}(95 \% \mathrm{CI})$ & RERI (95\%CI) \\
\hline \multicolumn{9}{|c|}{ Smoking } \\
\hline Never & $\mathrm{TT}+\mathrm{CT}$ & $561(51.9)$ & $285(40.1)$ & Ref & 0.060 & $2.43(1.85-3.01)^{*}$ & $0.41(0.22-0.61)^{*}$ & $1.38(0.37-2.40)^{*}$ \\
\hline Ever & $\mathrm{TT}+\mathrm{CT}$ & $239(22.1)$ & $166(23.4)$ & $1.53(1.12-2.08)$ & & & & \\
\hline Never & $\mathrm{CC}$ & 207(19.1) & $148(20.8)$ & $1.45(1.12-1.88)$ & & & & \\
\hline Ever & $\mathrm{CC}$ & $75(6.9)$ & $112(15.8)$ & $3.05(2.07-4.50)$ & & & & \\
\hline \multicolumn{9}{|c|}{ Drinking } \\
\hline Never & $\mathrm{TT}+\mathrm{CT}$ & $583(53.9)$ & $328(46.1)$ & Ref & 0.106 & $2.44(1.06-3.81)^{*}$ & $0.26(-0.02-0.53)$ & $0.45(-0.14-1.03)$ \\
\hline Ever & $\mathrm{TT}+\mathrm{CT}$ & $217(20.1)$ & $123(17.3)$ & $0.84(0.61-1.14)$ & & & & \\
\hline Never & $\mathrm{CC}$ & $205(19.0)$ & $166(23.4)$ & $1.50(1.17-1.92)$ & & & & \\
\hline Ever & $\mathrm{CC}$ & $77(7.1)$ & $94(13.2)$ & $1.68(1.16-2.43)$ & & & & \\
\hline
\end{tabular}

aAdusted by gender,age, stage and drinking or smoking.

*Statistically significant.

risk for $\mathrm{PC}$ compared to those with $\mathrm{CC}$ genotype [OR 0.59(95\%CI: 0.48-0.73), FDR-P = 1.5E-05].

\section{Gene-environment interactions with respect to PC risk}

Table 4 shows the results of our multiplicative and additive interaction analyses between rs2074733 and smoking or drinking in the combined group. Smoking had a synergic additive interaction with the $\mathrm{CC}$ genotype of rs2074733. Compared to nonsmokers with one or two $\mathrm{T}$ alleles, there were higher risks of $\mathrm{PC}$ among smokers with one or two $\mathrm{T}$ alleles, nonsmokers with the $\mathrm{CC}$ genotype, and smokers with the CC genotype. The ORs were 1.53 (95\% CI: 1.12-2.08), 1.45 (95\%CI: 1.12-1.88) and $3.05(95 \% \mathrm{CI}: 2.07-4.50)$, respectively. The SI, the attributable proportion due to interaction (AP) and the relative excess risk due to interaction (RERI) were
2.43 (95\%CI: $1.85-3.01), 1.38$ (95\%CI: $0.37-2.40)$, and 0.41 (95\%CI: $0.22-0.61)$, respectively. Moreover, we observed an positive additive interaction between drinking and rs2074733 in the combined population too. Compared to non-drinkers with one or two $\mathrm{T}$ alleles, the ORs for drinkers with one or two T alleles, nondrinkers with the $\mathrm{CC}$ genotype, and drinkers with the $\mathrm{CC}$ genotype were 0.84 (95\%CI: $0.61-1.14), 1.50$ (95\% CI: $1.17-1.92)$ and 1.68 (95\%CI: 1.16-2.43), respectively. The SI was 2.44 (95\%CI: 1.06-3.81).

\section{DISCUSSION}

This two-stage case-control study in two independent Chinese populations investigated whether the potential functional SNPs of six U2-dependent spliceosome genes could be associated with PC. A reproducible association between rs 2074733 of SF3A1 
and PC risk in both populations was identified. And potential synergic additive interactions between CC genotype and smoking/drinking status were found. This is the first study to show a SNP of SF3A1 and its interaction with smoking/drinking and the risk of PC in central and northern Chinese populations.

SF3A1 encodes subunit 1 of the splicing factor $3 a$ heterotrimer, which can facilitate the binding of the U2 snRNP to the 3'SS with SF3b1. Studies have shown that the SF3a heterotrimer is necessary for the in vitro conversion of the 15S U2 snRNP into the active 17S particle, which performs pre-mRNA splicing and the knockdown of single SF3 subunits blocks splicing [20]. Population studies have revealed that SF3A1 expression may be up-regulated in head and neck cancers, rectal carcinomas, and human non-small and small-cell lung cancers [21-23]. The aberrant expression of splicing factors, including SF3A1, are known to modify splice site selection [24], thereby influence the splicing of oncogenes and tumor suppressors, and induce the production of mRNA isoforms. This could contribute directly or indirectly to the development, progression and therapeutic response of cancers [25]. For example, the abnormal expression of SR family proteins (e.g., SRSF1 and SRSF3) in various human tumors was found to affect the alternative splicing of cancer-related genes, such as RON, BIN1, MNK2, S6K1, KLF6, FoxM1 and HIPK2, thereby creating protein isoforms that could contribute to the proliferation, avoidance of apoptosis, cell cycle modulation, or signal transduction of tumor cells [26-30]. Through our bioinformatic analysis, three SNPs rs5753071, rs10376 and rs10427610 were in complete linkage disequilibrium with rs2074733. They were reported to locate at the site of transcription factor binding, histone modification and open chromatin. And evidence suggested they acted as expression quantitative trait loci for the SF3A1 gene [31]. Notably, rs2074733 is located at $22 \mathrm{q} 12.2$, which is reportedly associated with the occurrence of lung cancer in Han Chinese [32]. Thus, genetic variants rs2074733 in SF3A1 may be involved in other cancer types beyond PC. Future studies are warranted to determine whether changes in SF3A1 can alter the splicing of specific oncogenes or tumor suppressors to promote PC.

We observed synergistic effects between smoking/ drinking and rs2074733. These findings seem biologically plausible. First, smoking is the only confirmed environmental risk factor for PC. Although the underlying mechanisms are poorly understood, a higher frequency of splicing variants for the MDM2 oncogene has been observed in tumors induced in smokers than those in nonsmokers [33]. Its over expression reportedly contributes to pancreatic neoplastic transformation [34], and its splicing variants may promote p53-independent cell growth, inhibit apoptosis and contribute to tumorigenesis [35]. Furthermore, an in vitro study showed that the activated carcinogenic metabolites of polycyclic aromatic hydrocarbons can induce alternative splicing of MDM2 [33]. In the context of drinking, alcohol consumption has been shown to modulate numerous genes in terms of their transcript levels and the ratios of their splice variants [36]. Thus, smoking and drinking may alter the splicing of specific oncogenes and tumor suppressors, increasing the risk of tumorigenesis among subjects with the risk variant of rs2074733 in SF3A1.

Two other SNPs of SF3A1 (rs5994293 and rs9608886), which also locate to the region of 22q12.2, were significantly associated with PC in screening population. However, these associations were not replicated in validation population. The same phenomenon was observed for PRPF40B rs4073998 and SRSF1 rs8819, suggesting that these positive associations in screening population may have been due to chance. In the future, additional studies in diverse populations, including PC patients with different stages, should be conducted to examine the possible associations between PC and these SNPs.

\section{MATERIALS AND METHODS}

\section{Study subjects}

In this two-stage case-control study, screening population was conducted among 298 PC patients and 525 cancer-free controls from Central China. Patients were consecutively recruited from January 2008 to September 2012 at Tongji Hospital (Huazhong University of Science and Technology, Wuhan, China). The controls were cancerfree volunteers randomly selected from heath examination programs given during the same period, part of which also included in our previous case-control studies [37]. Then, 413 PC patients and 557 cancer-free controls from North China were genotyped for validation. All cases were enrolled from January 2008 to December 2012 at Peking Union Medical College Hospital. The controls were cancer-free individuals selected from a community cancer-screening program for early detection, offered in the same region during the same time. All the PC patients in the two stages were diagnosed with pancreatic ductal adenocarcinoma by histopathologic examination of biopsy or resected tissue specimens, diagnostic imaging studies (computed tomography scan, ultrasound, and endoscopic retrograde cholangiopancreatography or magnetic resonance cholangiopancreatography, or exploratory laparotomy.

All enrolled subjects were unrelated Han Chinese. The cases were primary incident pancreatic ductal adenocarcinoma patients. The blood was collected prior to radiotherapy/chemotherapy. The cancer-free controls were frequency-matched to the cases by age ( \pm 5 years) and gender. Prior to recruitment, written informed consent was obtained from each subject, and information on demographic characteristics (e.g., gender, age, smoking status, and drinking status) was collected in a face-toface interview. Regular smoking is defined as at least one 
cigarette a day and for a year or more. Regular drinking is defined as drinking at least once a day for three consecutive months or more. This study was approved by the institutional review boards of Chinese Academy of Medical Sciences Cancer Institute and the Tongji Medical College of Huazhong University of Science and Technology. All the methods were performed in accordance with the approved guidelines and regulations.

\section{SNP selection and genotyping}

To choose candidate SNPs from the selected genes (SRSF1, SRSF2, SF3A1, SF3B1, SF1 and PRPF40B), we integrated information from the Haploview 4.2 (http://www .broadinstitute.org/scientific-community/science/programs/ medical-and-population-genetics/haploview/haploview) [38] and SNP info (http://snpinfo.niehs.nih.gov/snpinfo/snpfunc. htm) [39] databases.

First, SNP data for the candidate gene regions were downloaded from the Hapmap database for the Chinese Han Beijing population (Release 27 phase I+II+III; http:// www.HapMap.org) . The Haploview 4.2 software was then used to select tagSNPs based on the criteria of $r^{2}>0.8$ and a minor allele frequency $(\mathrm{MAF})>0.05$. We selected a total of 82 tagSNPs covering the six candidate genes. Thereafter, we used the SNPinfo database to prioritize the 82 tagSNPs by predicting their potential functions, which included splicing regulation, stop codon, polyphen prediction, transcription factor-binding motif, micro RNA binding site, amino acid substitution, and other functional effects. Finally, we selected 17 SNPs for genotyping of the screening population (Supplementary Table S1) using the TaqMan Openarray assay system (Applied Biosystems, Foster City, CA, USA). Thereafter, the five most positive SNPs were genotyped using TaqMan Real-time Polymerase Chain Reaction (RT-PCR, Applied Biosystems, Foster City, CA, USA) in the validation population. To ensure the accuracy of genotyping, quality control was monitored by including 5\% random duplicate samples; these duplicates yielded a concurrence rate of $100 \%$ (data not shown). We excluded SNPs that had genotype call rates of $<95 \%$ or showed deviation from HWE.

\section{Statistical analysis}

For each tagSNP, we evaluated HWE in both control groups using a goodness-of-fit chi-square test. In both populations, $t$-test was used to compare the difference of age distribution between cases and controls. Pearson chi-square tests were used to detect differences between cases and controls in the distributions of gender, smoking status, drinking status and SNPs. Unconditional logistic regression was used to calculate the ORs and their 95\% CIs for associations between genotypes and PC in both stages after adjustment for covariates (i.e., age, gender, drinking status, and smoking status). A two-tailed $P<0.05$ was used as the criterion of statistical significance. False discovery rate (FDR) is the expected ratio of erroneous rejections of the null hypothesis to the total number of rejected hypothesis among all the genes or SNPs analyzed in this study. The Benjamini and Hochberg method was used to calculate FDR values using in SAS [40]. All P values were adjusted by FDR, and we adjusted the $P$ values in the validation stage and combined stage together with the $P$ values in the screening stage.

Before we combined the populations of the two stages, the Breslow-Day test [41] was used to assess the homogeneity of the ORs in the two populations. And we added the stage for adjustment in the combined analysis [42]. Multiplicative and additive interactions were tested to evaluate positive interactions between genes and environmental factors. Multiple logistic regression models were used to detect the potential multiplicative interactions, and the log likelihood ratio (LLR) was used to assess whether the model was significantly improved by adding an additional interaction term. SI, AP, and RERI were evaluated in additive interaction analyses. Lack of interaction is indicated by $\mathrm{SI}=1, \mathrm{AP}=0$ and RERI $=0$ [43]. All statistical analyses were conducted using the SAS9.2 software (SAS Institute, Cary, NC, USA). The linkage disequilibrium of the SNPs was estimated using the Haploview4.2 software. The additive interaction analysis was performed using the R3.0.0 software (http://www.r-project.org/).

\section{CONCLUSIONS}

We herein report SF3A1 rs2074733 as a new susceptibility locus for PC that shows additive interactions with smoking and alcohol drinking. These findings support the potential importance of genetic variants of splicing factors in PC and could help increase the personalization of strategies to prevent PC. Although SNPs with rare polymorphisms may have been missed in this study, our results suggest that additional studies with larger sample sizes should use targeted SNP fine mapping to further identify true causal variants, especially in $22 q 12.2$. Furthermore, additional functional studies are warranted to verify the biological mechanism(s) underlying the interactions between smoking, drinking and spliceosome gene polymorphisms.

\section{ACKNOWLEDGMENT}

This work was supported by National Natural Science Foundation of China (NSFC - 81041079) for Li Wang and National Program for Support of Top-notch Young Professionals, National High-Tech Research and Development Program of China 2014AA020609 and Specialized Research Fund for the Doctoral Program of Higher Education 20130142110017 for Xiaoping Miao. 


\section{CONFLICTS OF INTEREST}

The authors declare no conflicts of interest.

\section{Authors' contributions}

LW and XPM designed the study. JT and YPL performed the DNA genotyping, data analysis and drafted the manuscript. BZ, YT, RZ performed the DNA genotyping. WC, LZ, NS prepared the DNA samples and collected the information. JMQ, XHL, and HL recruited the subjects in our study.

\section{REFERENCES}

1. Hidalgo M. Pancreatic cancer. The New England journal of medicine. 2010; 362:1605-1617.

2. Siegel R, Naishadham D, Jemal A. Cancer statistics, 2013. CA: a cancer journal for clinicians. 2013; 63:11-30.

3. Wang L, Yang GH, Lu XH, Huang ZJ, Li H. Pancreatic cancer mortality in China (11-2000). World journal of gastroenterology : WJG. 2003; 9:1819-1823.

4. Zou L, Zhong R, Shen N, Chen W, Zhu B, Ke J, Lu X, Zhang T, Lou J, Wang Z, Liu L, Qi L, Miao X. Non-linear dose-response relationship between cigarette smoking and pancreatic cancer risk: evidence from a meta-analysis of 42 observational studies. European journal of cancer. 2014; 50:193-203.

5. Hahn SA, Greenhalf B, Ellis I, Sina-Frey M, Rieder H, Korte B, Gerdes B, Kress R, Ziegler A, Raeburn JA, Campra D, Grutzmann R, Rehder H, Rothmund M, Schmiegel W, Neoptolemos JP, et al. BRCA2 germline mutations in familial pancreatic carcinoma. Journal of the National Cancer Institute. 2003; 95:214-221.

6. Jones S, Hruban RH, Kamiyama M, Borges M, Zhang X, Parsons DW, Lin JC, Palmisano E, Brune K, Jaffee EM, Iacobuzio-Donahue CA, Maitra A, Parmigiani G, Kern SE, Velculescu VE, Kinzler KW, et al. Exomic sequencing identifies PALB2 as a pancreatic cancer susceptibility gene. Science. 2009; 324:217.

7. Amundadottir L, Kraft P, Stolzenberg-Solomon RZ, Fuchs CS, Petersen GM, Arslan AA, Bueno-de-Mesquita HB, Gross M, Helzlsouer K, Jacobs EJ, LaCroix A, ZhengW, Albanes D, Bamlet W, Berg CD, Berrino F, et al. Genome-wide association study identifies variants in the $\mathrm{ABO}$ locus associated with susceptibility to pancreatic cancer. Nature genetics. 2009; 41:986-990.

8. Wu C, Miao X, Huang L, Che X, Jiang G, Yu D, Yang X, Cao G, Hu Z, Zhou Y, Zuo C, Wang C, Zhang X, Zhou Y, $\mathrm{Yu}$ X, Dai W, et al. Genome-wide association study identifies five loci associated with susceptibility to pancreatic cancer in Chinese populations. Nature genetics. 2012; 44:62-66.
9. Petersen GM, Amundadottir L, Fuchs CS, Kraft P, Stolzenberg-Solomon RZ, Jacobs KB, Arslan AA, Buenode-Mesquita HB, Gallinger S, Gross M, Helzlsouer K, Holly EA, Jacobs EJ, Klein AP, LaCroix A, Li D, et al. A genome-wide association study identifies pancreatic cancer susceptibility loci on chromosomes 13q22.1, 1q32.1 and 5p15.33. Nature genetics. 2010; 42:224-228.

10. Garraway LA, Lander ES. Lessons from the cancer genome. Cell. 2013; 153:17-37.

11. Padgett RA. New connections between splicing and human disease. Trends in genetics : TIG. 2012; 28:147-154.

12. Quesada V, Conde L, Villamor N, Ordonez GR, Jares P, Bassaganyas L, Ramsay AJ, Bea S, Pinyol M, MartinezTrillos A, Lopez-Guerra M, Colomer D, Navarro A, Baumann T, Aymerich M, Rozman M, et al. Exome sequencing identifies recurrent mutations of the splicing factor SF3B1 gene in chronic lymphocytic leukemia. Nature genetics. 2012; 44:47-52.

13. Wang L, Lawrence MS, Wan Y, Stojanov P, Sougnez C, Stevenson K, Werner L, Sivachenko A, DeLuca DS, Zhang L, Zhang W, Vartanov AR, Fernandes SM, Goldstein NR, Folco EG, Cibulskis K, et al. SF3B1 and other novel cancer genes in chronic lymphocytic leukemia. The New England journal of medicine. 2011; 365:2497-2506.

14. Yoshida K, Sanada M, Shiraishi Y, Nowak D, Nagata Y, Yamamoto R, Sato Y, Sato-Otsubo A, Kon A, Nagasaki M, Chalkidis G, Suzuki Y, Shiosaka M, Kawahata R, Yamaguchi T, Otsu M, et al. Frequent pathway mutations of splicing machinery in myelodysplasia. Nature. 2011; 478:64-69.

15. Imielinski M, Berger AH, Hammerman PS, Hernandez B, Pugh TJ, Hodis E, Cho J, Suh J, Capelletti M, Sivachenko A, Sougnez C, Auclair D, Lawrence MS, Stojanov P, Cibulskis K, Choi K, et al. Mapping the hallmarks of lung adenocarcinoma with massively parallel sequencing. Cell. 2012; 150:1107-1120.

16. Ellis MJ, Ding L, Shen D, Luo J, Suman VJ, Wallis JW, Van Tine BA, Hoog J, Goiffon RJ, Goldstein TC, Ng S, Lin L, Crowder R, Snider J, Ballman K, Weber J, et al. Whole-genome analysis informs breast cancer response to aromatase inhibition. Nature. 2012; 486:353-360.

17. Harbour JW, Roberson ED, Anbunathan H, Onken MD, Worley LA, Bowcock AM. Recurrent mutations at codon 625 of the splicing factor SF3B1 in uveal melanoma. Nature genetics. 2013; 45:133-135.

18. Biankin AV, Waddell N, Kassahn KS, Gingras MC, Muthuswamy LB, Johns AL, Miller DK, Wilson PJ, Patch AM, Wu J, Chang DK, Cowley MJ, Gardiner BB, Song S, Harliwong I, Idrisoglu S, et al. Pancreatic cancer genomes reveal aberrations in axon guidance pathway genes. Nature. 2012; 491:399-405.

19. Tian J, Zhu B, Tian Y, Zhong R, Miao X, Wang L. [Association between pancreatic cancer risk and the 
interaction of U2AF65 gene polymorphisms and smoking]. Zhonghua liu xing bing xue za zhi = Zhonghua liuxingbingxue zazhi. 2014; 35:710-713.

20. Tanackovic G, Kramer A. Human splicing factor SF3a, but not SF1, is essential for pre-mRNA splicing in vivo. Molecular biology of the cell. 2005; 16:1366-1377.

21. Difilippantonio S, Chen Y, Pietas A, Schluns K, PacynaGengelbach M, Deutschmann N, Padilla-Nash HM, Ried T, Petersen I. Gene expression profiles in human non-small and small-cell lung cancers. European journal of cancer. 2003; 39:1936-1947.

22. Chin D, Boyle GM, Williams RM, Ferguson K, Pandeya N, Pedley J, Campbell CM, Theile DR, Parsons PG, Coman WB. Novel markers for poor prognosis in head and neck cancer. International journal of cancer Journal international du cancer. 2005; 113:789-797.

23. Rimkus C, Friederichs J, Boulesteix AL, Theisen J, Mages J, Becker K, Nekarda H, Rosenberg R, Janssen KP, Siewert JR. Microarray-based prediction of tumor response to neoadjuvant radiochemotherapy of patients with locally advanced rectal cancer. Clinical gastroenterology and hepatology : the official clinical practice journal of the American Gastroenterological Association. 2008; 6:53-61.

24. Matlin AJ, Clark F, Smith CW. Understanding alternative splicing: towards a cellular code. Nature reviews Molecular cell biology. 2005; 6:386-398.

25. Grosso AR, Martins S, Carmo-Fonseca M. The emerging role of splicing factors in cancer. EMBO reports. 2008; 9:1087-1093.

26. Ghigna C, Giordano S, Shen H, Benvenuto F, Castiglioni F, Comoglio PM, Green MR, Riva S, Biamonti G. Cell motility is controlled by SF2/ASF through alternative splicing of the Ron protooncogene. Molecular cell. 2005; 20:881-890.

27. Karni R, de Stanchina E, Lowe SW, Sinha R, Mu D, Krainer AR. The gene encoding the splicing factor SF2/ ASF is a proto-oncogene. Nature structural \& molecular biology. 2007; 14:185-193.

28. Shi J, Hu Z, Pabon K, Scotto KW. Caffeine regulates alternative splicing in a subset of cancer-associated genes: a role for SC35. Molecular and cellular biology. 2008; 28:883-895.

29. Jia R, Li C, McCoy JP, Deng CX, Zheng ZM. SRp20 is a proto-oncogene critical for cell proliferation and tumor induction and maintenance. International journal of biological sciences. 2010; 6:806-826.

30. Kurokawa K, Akaike Y, Masuda K, Kuwano Y, Nishida K, Yamagishi N, Kajita K, Tanahashi T, Rokutan K. Downregulation of serine/arginine-rich splicing factor 3 induces G1 cell cycle arrest and apoptosis in colon cancer cells. Oncogene. 2014; 33:1407-1417.

31. Orozco G, Viatte S, Bowes J, Martin P, Wilson AG, Morgan AW, Steer S, Wordsworth P, Hocking LJ, consortium $\mathrm{U}$, consortium W, consortium B, Barton A, Worthington J, Eyre S. Novel RA susceptibility locus at 22 q12 identified in an extended UK genome wide association study. Arthritis and rheumatism. 2014; 66:24-30.

32. Hu Z, Wu C, Shi Y, Guo H, Zhao X, Yin Z, Yang L, Dai J, Hu L, Tan W, Li Z, Deng Q, Wang J, Wu W, Jin G, Jiang Y, et al. A genome-wide association study identifies two new lung cancer susceptibility loci at 13q12.12 and 22q12.2 in Han Chinese. Nature genetics. 2011; 43:792-796.

33. Weng MW, Lai JC, Hsu CP, Yu KY, Chen CY, Lin TS, Lai WW, Lee H, Ko JL. Alternative splicing of MDM2 mRNA in lung carcinomas and lung cell lines. Environmental and molecular mutagenesis. 2005; 46:1-11.

34. Ebert M, Yokoyama M, Kobrin M, Friess H, Buchler M, Korc M. Increased mdm 2 expression and immunoreactivity in human pancreatic ductal adenocarcinoma. International journal of oncology. 1994; 5:1279-1284.

35. Steinman HA, Burstein E, Lengner C, Gosselin J, Pihan G, Duckett CS, Jones SN. An alternative splice form of Mdm2 induces p53-independent cell growth and tumorigenesis. The Journal of biological chemistry. 2004; 279:4877-4886.

36. Sasabe T, Ishiura S. Alcoholism and alternative splicing of candidate genes. International journal of environmental research and public health. 2010; 7:1448-1466.

37. Zhu B, Tian J, Zhong R, Tian Y, Chen W, Qian J, Zou L, Xiao M, Shen N, Yang H, Lou J, Qiu Q, Ke J, Lu X, SongW, Li H, et al. Genetic variants in the SWI/SNF complex and smoking collaborate to modify the risk of pancreatic cancer in a Chinese population. Molecular carcinogenesis. 2015; 54:761-768.

38. Barrett JC, Fry B, Maller J, Daly MJ. Haploview: analysis and visualization of LD and haplotype maps. Bioinformatics. 2005; 21:263-265.

39. Xu Z, Taylor JA. SNPinfo: integrating GWAS and candidate gene information into functional SNP selection for genetic association studies. Nucleic acids research. 2009; 37:W600-605.

40. Benjamini Y, Hochberg Y. Controlling the False Discovery Rate - a Practical and Powerful Approach to Multiple Testing. J Roy Stat Soc B Met. 1995; 57:289-300.

41. Breslow NE, Day NE. Statistical methods in cancer research. Volume II-The design and analysis of cohort studies. IARC scientific publications. 1987; 82:1-406.

42. Blettner M, Sauerbrei W, Schlehofer B, Scheuchenpflug T, Friedenreich C. Traditional reviews, meta-analyses and pooled analyses in epidemiology. International journal of epidemiology. 1999; 28:1-9.

43. Kallberg H, Ahlbom A, Alfredsson L. Calculating measures of biological interaction using R. European journal of epidemiology. 2006; 21:571-573. 